\title{
PENERAPAN APLIKASI ANDROID "OJEK GT" SEBAGAI STARTUP INDUSTRI KREATIF MENUJU SOCIETY 5.0
}

\author{
Riovan Styx Roring \\ Dosen Universitas Mulia \\ Jalan ZA Maulani No. 9 Damai Bahagia, Balikpapan, Kalimantan Timur, Indonesia \\ Sur-el : riovan@universitasmulia.ac.id
}

\begin{abstract}
Implementation of technology that supports Society 5.0 needs to be done because the principal itself that focused towards technology implementation and not inclined emphasize to the technology development. Furthermore, 5.0 era also priotize technology implementation to all element of the society that could be used by diverse aspect in the community, such as: economics, education. Infrastructure, and community expertises. One of the support technology utilization is Costless Transportation Application Ojek GT base don Android Client and PHP: Hypertext Preporcessor (PHP) Web as server. This application designed using both of the platform above to fulfill the user's need. Both of the platform are integrated using Application Programming Interface (API) as a data exchange medium to the database. The implementation of the software itself follows the Community Service Freedom Technology (CSFT) that designed as software development pattern which aims to push support technology utilization towards Society 5.0 era. In the future, this software is expected to be a simple of support technology utilization in Society 5.0 era that could be implemented to all the aspect in the community cope. Beside as a solution of costless technology utilization, Ojek GT could also be expected as Business Startup in the creative industry scope.
\end{abstract}

Keywords: Society 5.0, Android, PHP, API, Ojek GT

\begin{abstract}
Abstrak : Penerapan teknologi pendukung era Society 5.0 perlu dilakukan karena prinsipnya yang fokus terhadap penerapan teknologi dan tidak cenderung menitikberatkan pada pengembangan teknologi. Selain itu, era 5.0 juga memprioritaskan penerapan teknologi ke semua unsur masyarakat sehingga dapat dimanfaatkan oleh beragam aspek di masyarakat seperti: ekonomi, pendidikan, infrastruktur, dan keahlian masyarakat. Salah satu pemanfaatan teknologi pendukung ini yaitu Aplikasi Transportasi Gratis Ojek GT berbasis Android Client dan Web PHP: Hypertext Preprocessor (PHP) sebagai server. Aplikasi ini dirancang menggunakan kedua platform diatas untuk memenuhi kebutuhan pengguna. Kedua platform ini diintegrasikan menggunakan Application Programming Interface (API) sebagai sarana pertukaran data ke database. Penerapan aplikasi ini mengikuti prinsip Community Service Freedom Technology (CSFT) yang dirancang sebagai pola pengembangan aplikasi yang bertujuan untuk mendorong pemanfaatan teknologi menuju era Society 5.0.

Diharapkan kedepannya aplikasi ini bisa menjadi contoh pemanfaatan teknologi pendukung era Society 5.0 yang dapat diterapkan pada semua aspek yang ada di ruang lingkup kehidupan masyarakat. Selain sebagai solusi pemanfaatan teknologi secara gratis, Ojek GT ini juga diharapkan bisa menjadi Startup Bisnis dalam ruang lingkup industri kreatif.
\end{abstract}

Kata kunci: Society 5.0, Android, PHP, API, Ojek GT

\section{PENDAHULUAN}

Seiring perkembangan teknologi yang begitu pesat, terlebih dengan terjadinya revolusi industri 4.0 yang menyebabkan pergeseran ekonomi. Ekonomi yang dahulunya dikuasai oleh usaha-usaha besar mulai bergeser kepada perkembangan ekonomi melalui usaha-usaha menengah, kecil, dan mikro (UMKM) yang dikelola langsung oleh masyarakat menengah ke bawah. Masyarakat mulai menyadari bahwa teknologi sangat berperan penting dalam 
perkembangan usahanya. Kebutuhan pengusaha akan Big Data, Software as a Services (SAAS), ecommerce, dan teknologi informasi lainnya tidak lagi menjadi kebutuhan yang hanya diperlukan oleh usaha besar melainkan menjadi kebutuhan pokok UMKM dalam mengembangkan bisnisnya. Hadirnya perangkat lunak-perangkat lunak yang khusus digunakan oleh UMKM, menjadi senjata andalan masyarakat dalam mengembangkan usahanya sehingga terjadi pergeseran ekonomi seperti yang terjadi sekarang ini.

Melalui perkembangan tersebut maka perlu disadari bahwa kebutuhan masyarakat dalam pemanfaatan teknologi informasi pun ikut meningkat. Kebutuhan-kebutuhan ini meliputi pemanfaatan sumber daya manusia (SDM) maupun infrastruktur penunjang dalam berbagai bidang teknologi informasi seperti multimedia, audit dan tata kelola teknologi informasi, sistem pendukung keputusan, perangkat lunak dengan pemrograman berorientasi obyek, manajemen konten web, dll.

Inkubator Bisnis di Universitas Mulia kemudian dicetus untuk menjawab kebutuhankebutuhan masyarakat diatas melalui startup startup yang dikelola oleh mahasiswa sebagai perpanjangan tangannya. Inkubator ini tidak hanya menunjang startup melalui pemanfaatan teknologi informasi dengan prinsip Global Technopreneur di era revolusi industri 4.0, melainkan inkubator ini juga mulai mempersiapkan teknologi pendukung usaha menuju era revolusi society 5.0 dengan memperkenalkan Community Service Freedom Technology (CSFT) sebagai landasan inkubator dengan prinsip pengabdian kepada masyarakat (community service).

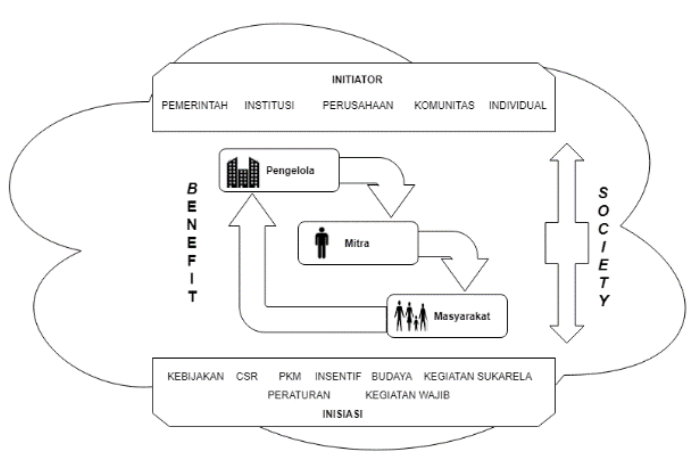

Gambar 1. Community Service Freedom Technology (CSFT)

Prinsip Global Technopreneur merupakan prinsip pengembangan kewirausahaan berbasis teknologi informasi secara global. Pelaku usaha yang mencakup masyarakat pada umumnya dan mahasiswa pada khususnya akan disiapkan melalui dukungan pelatihan, teknologi, jaringan bisnis, maupun inkubasi bisnis untuk pengembangan usahanya di era revolusi industri 4.0 menuju revolusi society 5.0.

Konsep Society 5.0 tidak seperti Industri 4.0 yang terbatas pada sektor manufaktur, namun memecahkan masalah sosial dengan bantuan dari integrasi ruang fisik dan virtual[1]. Society 5.0 ini adalah masyarakat yang dimana teknologi informasi tingkat lanjut, Internet of Things (IOT), robot-robot, kecerdasan buatan, dan Augmented Reality (AR) digunakan secara aktif dikehidupan secara umum, di dalam industri, kesehatan, dan bidang lainnya yang tidak bertujuan untuk pengembangan teknologi, namun lebih terhadap benefit dan kenyamanan setiap orang.

Salah satu aplikasi yang dirancang dan diinkubasi oleh Inkubator Bisnis adalah Ojek GT. Ojek GT ini merupakan aplikasi transportasi 
online dengan penerapan CSFT sehingga dapat menyediakan layanan secara gratis. Aplikasi ini diharapkan menjadi solusi untuk permasalahanpermasalahan ekonomi yang terjadi dan juga penggerak ditengah pandemi yang terjadi saat ini.

\section{METODOLOGI PENELITIAN}

Penelitian ini dilakukan dengan pendekatan kualitatif, dimana peneliti mencoba untuk mengumpulkan data-data yang akan digunakan dalam proses pengembangan aplikasi. Fokus penelitian ini untuk mengembangkan aplikasi sesuai dengan alur sistem CSFT.

Sedangkan untuk pengumpulan data, penelitian ini menggunakan beberapa metode, yaitu:

1. Observasi, dimana data dikumpulkan dengan cara mengamati secara daring atau secara luring pada objek penelitian.

2. Semi Structured Interview, peneliti akan menyiapkan beberapa pertanyaanpertanyaan mengenai pelaku usaha. Meskipun kumpulan pertanyaan telah disiapkan, wawancara dapat berkembang kedalam suatu topik yang sesuai dengan kebutuhan kepada para ahli.

3. Studi Pustaka yaitu mencari informasi tentang teori-teori yang berhubungan dengan penelitian dari sumber seperti buku, artikel dan jurnal yang berkaitan dengan penelitian.

Berdasarkan kebutuhan diatas maka penelitian ini menggunakan System Development
Life-cycle (SDLC) yang menggunakan 6 aspek utama sebagai alur pengembangan perangkat lunak [2]. Keenam aspek utama disajikan pada gambar 2.

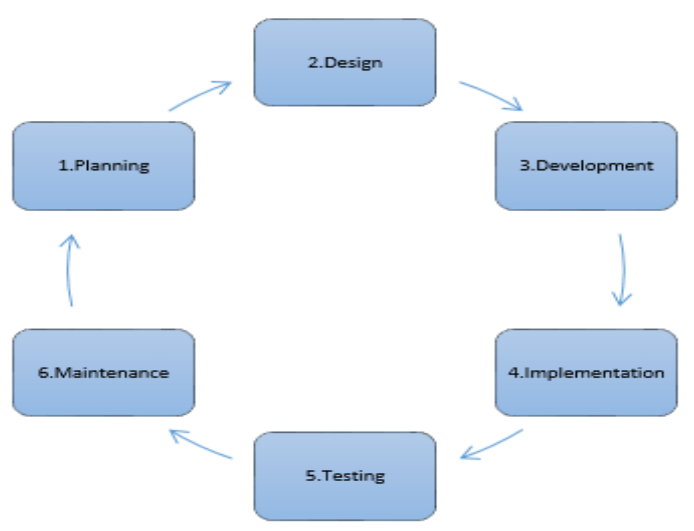

Gambar 2. System Development Life-cycle (SDLC)

Persiapan awal dalam pengembangan sistem adalah dengan mempersiapkan rencana pengumpulan data, pencatatan daftar kebutuhan dari perangkat lunak, perangkat keras, administrasi, maupun kebutuhan lainnya. Perencanaan juga akan melalui proses evaluasi dimana setiap task akan diberikan nilai kebutuhan.

Selain itu, dalam tahap ini penulis akan mengumpulkan data sebagai bahan perumusan permasalahan bisnis dan scope-nya, membuat daftar rencana pekerjaan, melakukan studi kelayakan proyek, dan melakukan inisiasi proyek.

Perancangan dilakukan setelah mendapatkan data/sample yang diperlukan. Perancangan meliputi aspek-aspek seperti kebutuhan pengguna, keleluasaan pengguna dalam menggunakan sistem dengan konsep responsive design, dan kemudahan akses pengguna. Perancangan juga akan menggunakan prinsip user-centered view, dimana pola pandang 
pengguna yang menentukan hasil akhir sistem. Perancangan sistem pada penelitian ini menggunakan model Unified Modeling Language (UML) dengan Use Case Diagram dan Entity Relationship Diagram (ERD).

Pada tahap implementasi, sistem akan diimplementasikan dengan bahasa pemrograman yang telah ditentukan yaitu pemrograman PHP dengan Framework Codeigniter sebagai akses untuk admin berbasis web, dan Android untuk klien dan driver. Framework ini merupakan alat bantu pemrograman PHP dengan pendekatan secara prosedural[3]. Hasil pengembangan sistem diharuskan telah dikonversi menjadi kode pada akhir tahap ini.

Metode pengujian yang digunakan pada penelitian ini yaitu dengan menggunakan pengujian kotak hitam (Black Box Testing). Black Box Testing adalah metode uji coba yang memfokuskan pada keperluan software. Metode pengujian kotak hitam berusaha untuk menemukan kesalahan dalam beberapa kategori, diantaranya fungsi-fungsi yang salah atau hilang, kesalahan interface, kesalahan dalam struktur data atau akses database, kesalahan performa dan kesalahan validasi data[4]. Black Box Testing adalah pengujian yang dilakukan hanya mengamati hasil eksekusi melalui data uji dan memeriksa fungsional dari perangkat lunak. Jadi dapat dianalogikan seperti melihat kotak hitam yang hanya dapat dilihat dari luar tanpa mengetahui isi dalam kotaknya. Sama seperti pengujian black box, mengevaluasinya hanya dari tampilan luarnya (interface-nya), fungsional tanpa mengetahui apa sesungguhnya yang terjadi dalam proses detailnya.
Tahapan terakhir yaitu Maintenance adalah proses setelah implementasi sistem yang idealnya dilakukan dalam beberapa periode tertentu. Maintenance dilakukan untuk menjaga kestabilan sistem dan juga mengembangkan sistem agar dapat sesuai dengan perkembangan jaman.

\section{HASIL DAN PEMBAHASAN}

\subsection{Gambaran Obyek Penelitian}

Institusi memprogramkan program pengembangan usaha produk intelektual kampus dengan prinsip Global Technopreneurship menuju Revolusi Society 5.0. Salah satu program utama yaitu implementasi CSFT sebagai salah satu wujud pengabdian kepada masyarakat sekaligus startup untuk persiapan revolusi society 5.0 .

Startup andalan program ini yaitu Ojek GT dengan tagline-nya "Ojeknya Gotong Royong, Ojeknya Gratis”. Ojek GT ini merupakan salah satu produk inovasi inkubasi institusi berbasis CSFT yang menyediakan layanan transportasi online secara gratis kepada seluruh elemen masyarakat. Layanan gratis ini merupakan implementasi CSFT yang berjalan melalui inisiasi dari elemen-elemen masyarakat yang diawali oleh institusi sebagai pengelola, mahasiswa sebagai mitra, dan masyarakat pada umumnya sebagai pengguna.

Kedepannya institusi berencana untuk mengembangkan startup-startup berbasis CSFT di berbagai ruang lingkup usaha seperti: pembangunan, layanan rumahan, pengabdian kepada masyarakat, ritel, dll. Selain itu, institusi 
akan menggandeng berbagai elemen sebagai inisiator seperti: pemerintah, organisasi, perusahaan, komunitas, maupun individual untuk mengembangkan program berbasis CSFT ini.

\subsection{Penerapan Aplikasi}

Berdasarkan hasil observasi yang telah dilakukan, belum ditemukan adanya skema sistem pembayaran transportasi gratis yang telah diterapkan untuk obyek penelitian ini. Sistem pembayaran obyek ini merupakan ide baru yang akan dirancang dan disesuaikan berdasarkan hasil pengolahan data penelitian yang telah didapatkan.

Sedangkan rancangan fitur aplikasinya cenderung sama dengan fitur-fitur transportasi online pada umumnya. Aplikasi terbagi dalam tiga sistem, yaitu: sistem admin berbasis web, aplikasi klien berbasis android, dan aplikasi driver berbasis android.

Rancangan basis data dalam aplikasi ini tidak menggunakan relasi basis data (non relational database) karena data-data yang ada tidak terstruktur[5]. Basis data Ojek GT terdiri dari 28 tabel dan dirancang dalam basis data MySQL.

Basis data ini dirancang agar terhubung secara real-time ke tiga sistem diatas melalui fungsi Application Programming Interface (API). Fungsi ini digunakan untuk mempercepat proses pengembangan aplikasi dan mengintegrasikan sistem yang berbeda-beda.

\begin{tabular}{|c|c|c|c|c|c|c|}
\hline \multicolumn{7}{|c|}{ Untitled * } \\
\hline (6) & Vo ojekgtka data driver & Vo ojekgtka data customer & & 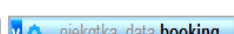 & W oiekotka data car type & Vo ojekgatka data user promotion \\
\hline 网 & 8 id : int(11) & id : int(11) & V o ojekgtka data service_log & id : int(11) & id : int(11) & 8 id : int(11) \\
\hline [at] & (1) driver_name : varchar(255) & (3) name : varchar(50) & $\begin{array}{l}8 \text { id : int(11) } \\
\text { 䀚 url : varchar(255) }\end{array}$ & 具 booking_id : varchar(50) & 目 name : varchar(50) & \# user_id : int(11) \\
\hline 固 & 自 name : varchar(250) & (1) phone : varchar(50) & (1) parameter : longtext & \# user_id : int(11) & (1) image : varchar(250) & \# promotion_code : int(50) \\
\hline 8 & \# car_id: int(11) & 目 email : varchar $(50)$ & auth : varchar(255) & B book_date : varchar $(100)$ & \# max_seat : int(50) & $\#$ use_ltd : int(25) \\
\hline 0 & 自 image : varchar(750) & - password : varchar(50) & (1) result : text & lor_type : varchar(50) & \# fare : double & \# default : int(11) \\
\hline -4) & 1) post_code : varchar (50) & $\begin{array}{l}\text { 1) image : varchar(250) } \\
\text { - user code : varchar(250) }\end{array}$ & 目 time : varchar(255) & \# driver_id : int(25) & \# min_fare : double & \multirow{5}{*}{$\begin{array}{l}\text { Vo ojekgtka data trip_feedback } \\
\text { id : int(11) } \\
\text { o trip_feedback : varchar(250) }\end{array}$} \\
\hline 目 & \multicolumn{2}{|c|}{ 自 vehicle_reg_no : varchar(25) a a user_code : varchar(250) } & \multirow{2}{*}{$\begin{array}{l}v \text { o ojekgtka data help_table } \\
\text { 8 id : int(10) }\end{array}$} & \# base_fare : double & \# km_fare : double & \\
\hline & 自 phone : varchar(25) & $\begin{array}{l}\# \text { status : int(11) } \\
\# \text { otp : int(11) }\end{array}$ & & \# km_fare : double & \# time_fare : double & \\
\hline 至 & 目 email : varchar(50) & $\begin{array}{l}\text { \# otp: int(11) } \\
\text { \# promo_usage_count : int(11) }\end{array}$ & 目 image : varchar(250) & \# min_fare : double & \# status : int(11) & \\
\hline 10 & 自 city : varchar(100) & $\begin{array}{l}\text { \# promo_usage_count : int(11) } \\
\text { 自 fcm token : text }\end{array}$ & lo head : varchar(250) & \# promotion_fare : double & & \\
\hline 国 & 目 state : varchar(50) & $\begin{array}{l}\text { 目 fcm_token : text } \\
\text { 自 promocode : varchar(100) }\end{array}$ & & \# sub_total_fare : double & Vo ojekgtka data feedback & V o ojekgtka_data driver_feedback \\
\hline & B password : varchar(50) & 国 promocode : varchar(100) & $\begin{array}{l}\text { 目 content : longtext } \\
\text { \# status : int(11) }\end{array}$ & \# fare : double & 8 id : int(11) & \# id : int(11) \\
\hline$\sqrt{4}$ & (1) address : text & v o ojekgtka_data driver_document & \# status : int(11) & \# total_km : double & \# cust_id : int(11) & 自 driver__ating : varchar(250) \\
\hline 0 & 自 driver_lat : varchar(255) & 8 id : int(10) & Vo ojekgtka data charge_condition & 1 - time : varchar(100) & \# trip_id : int(11) & vo ojekgtka data settings \\
\hline & (1) driver_Ing : varchar(255) & \# driver_id : int(10) & id : int(11) & _ start_time : varchar(100) & \# driver_id : int(11) & 8 id : int(11) \\
\hline () & (1) license_no : varchar(25) & 目 type : varchar(250) & \# pat_id: int(11) & (1) end time : varchar $(100)$ & \# rating : double & 目 title : varchar(500) \\
\hline (3) & \# status : int(11) & 目 image : varchar(750) & (1) start time : varchar(10) & (1) trip_start_time : varchar(100) & (] good_feedback : varchar(255) & 目 $\log 0: \operatorname{varchar}(500)$ \\
\hline A & \# book_status : int(11) & - ilatus : varchar(10) & (1) end_time : varchar(10) & trip_end_time : varchar(100) & (a) bad_feedback : varchar(255) & 自 favicon : varchar(500) \\
\hline 4 & \# is_online : int(11) & vo ojekgtka data driver_request & \# fare : double & 1) source : varchar(250) & 目 driver_feedback : longtext & $\# \operatorname{tax}: \operatorname{int}(10)$ \\
\hline$\oplus$ & 目 fcm_token : text & $\begin{array}{l}\text { V o opekgtka data driver_request } \\
\text { o id : int(11) }\end{array}$ & \# status : int(11) & destination : varchar(250) & 首 trip_report : varchar(255) & \# admin_charge : int(50) \\
\hline (1) & \# driver_type : int(10) & $\begin{array}{l}8 \text { id : int(11) } \\
\# \text { req_id : int(11) }\end{array}$ & Vo ojekgtka data address & 自 distance : varchar(100) & Vo jekgtka data rating & - booking_code : varchar(100) \\
\hline (1) & $\begin{array}{l}\text { \# is_deaf: int(11) } \\
\text { \# is flash required: int(11) }\end{array}$ & \# req_date : varchar(255) & id : int(11) & 目 source_lat: varchar(100) & 8 id : int(11) & 具 key : varchar(200) \\
\hline & \# is_flash_required : int(11) & \# driver_id : int(11) & \# cust_ id : int(11) & 1) source_lng : varchar(100) & $\#$ rating : int(50) & Vo ojekgtka data request \\
\hline$\theta$ & Vo ojekgtka data car & Vo ojekgtka data help_review & li work: varchar(100) & (1) destination_lat : varchar(100) & 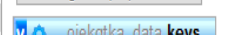 & id : int(11) \\
\hline Q & $\begin{array}{l}8 \text { id : int(11) } \\
\# \text { driv id : int(11) }\end{array}$ & 8 id : int(10) & home : varchar(100) & (1) destination_Ing : varchar(100) & Vo opekgtka data keys & $\#$ cust_id : int(11) \\
\hline & $\begin{array}{l}\text { \# driv_id : int(11) } \\
\text { \# type : int(11) }\end{array}$ & \# driver_id : int(10) & _ home_lat : varchar(25) & \# payment_status : int(11) & 8 id: int(11) & \# driver_id : int(11) \\
\hline (1) & $\begin{array}{l}\# \text { type : int(11) } \\
\text { model } \cdot \operatorname{varchar}(50)\end{array}$ & \# help_id : int(10) & home long : varchar(25) & \# status : int(11) & 目 security_key : varchar(40) & \# car_type : int(10) \\
\hline$\sharp$ & $\begin{array}{l}\text { 1) model : varchar }(50) \\
\text { car owner : varchar }(100)\end{array}$ & $\begin{array}{l}\text { \# help__d : int(10) } \\
\text { \# help_status : int(10) }\end{array}$ & (1) work_lat : varchar(25) & \# pattern_id : int(10) & \# level : int(2) & li source : varchar(250) \\
\hline & (1) car_owner : varchar $(100)$ & & work long: varchar(25) & \# fee $:$ int( $(50)$ & \# ignore_limits : tinyint(1) & destination : varchar(250) \\
\hline & 首 vehicle_reg_num : varchar(100) & & name : varchar(250) & $\# \operatorname{tax}: \operatorname{int}(50)$ & [1] date_created : timestamp & _ Source_lat: varchar(250) \\
\hline & $\#$ max_seat : int(50) & & \# type : int(11) & $\#$ discount : int(10) & & l ( source_Ing : varchar(250) \\
\hline & $\#$ min_fare : double & Do ojekgtka_data location & \# status : int(11) & \# payout : int(50) & V o jekgtha data roles & (1) destination_lat : varchar(250) \\
\hline & \# km_fare : double & & & \# cash_collection : int(10) & id : int(10) & 1) destination_Ing : varchar(250) \\
\hline & \# time_fare : double & Q jojekgtka_data promocode & Q ojekgtka_data pattern & \# car_arrival : int(10) & 自 role : varchar $(750)$ & \# status : int(11) \\
\hline & 目 image : varchar(250) & $\$ 0$ ojekgtka_data countries & elottka data admin users & (1) trip_path : longtext & (⿴) permission : varchar(750) & 目 trip_id : varchar(50) \\
\hline & \# status : int(11) & Oo jekgtka data driver online & 10 ojekgtra_data admin_users & & & \# pattern_id : int(10) \\
\hline
\end{tabular}

Gambar 3. Rancangan Basis Data Ojek GT 

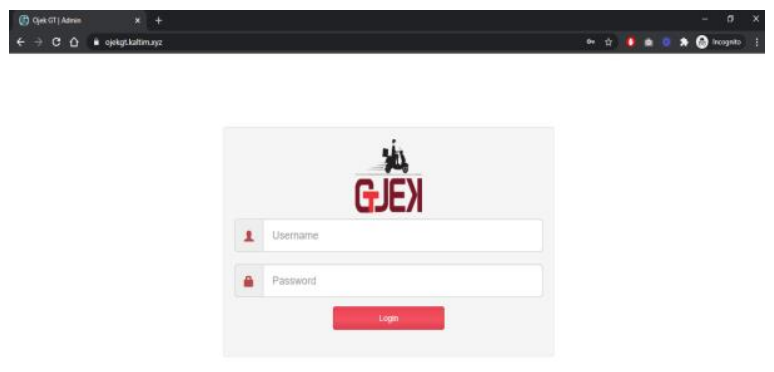

\section{Gambar 4. Halaman Login Admin}

Sistem admin ini digunakan untuk mengelola sistem secara keseluruhan melalui akses web yang dapat diakses melalui peramban komputer maupun smartphone. Admin dapat melakukan monitoring pesanan, pengelolaan customer, driver, daerah, promosi, dokumen driver, feedback, bantuan, request, pengaturan, dan profil admin.

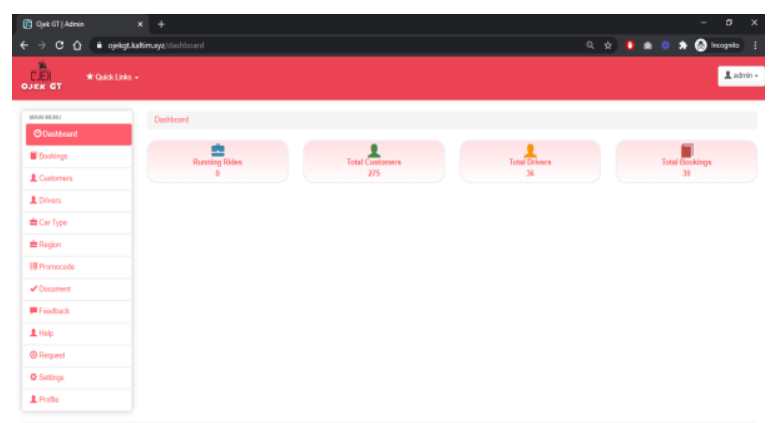

\section{Gambar 5. Halaman Utama Admin}

Pada halaman utama, admin dapat melihat sekilas informasi jumlah pesanan yang sedang terjadi, jumlah pelanggan, driver, dan total pesanan yang sudah selesai. Dalam sistem ini juga tersedia akses menu ke semua fitur yang disediakan sistem.

Selain melihat dan mengelola user, admin dapat melakukan verifikasi dokumen yang dikirimkan driver melalui aplikasi android dengan Representative State Transfer (REST) API [6]. Terdapat 12 dokumen yang harus dilengkapi driver sebelum dapat melayani penumpang. Adapun dokumen-dokumen itu, antara lain: Lembar Persetujuan, KTP, Formulir Cek Background, SIM, BPKB, NPWP, Asuransi, Formulir Ijin Kendaraan, Nomor Kendaraan, Surat Keterangan Sehat, SKCK, dan foto kendaraan.

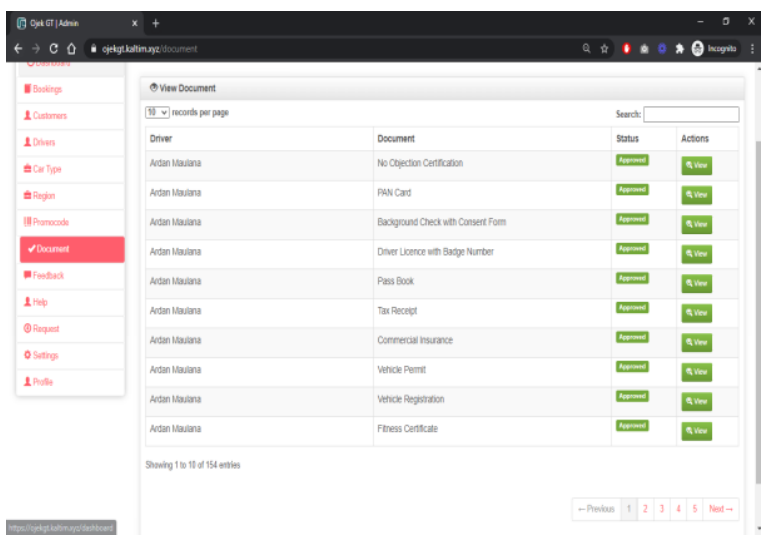

\section{Gambar 6. Verifikasi Dokumen Driver}

Selain itu, untuk kebutuhan pengelolaan wilayah operasi, sistem ini juga dikembangkan dengan integrasi Google API yang memiliki sistem prediksi untuk kendaraan yang baik [7]. API ini juga dikoneksikan langsung dengan aplikasi Android client dan driver.

Dalam sistem ini, peneliti menggunakan delapan Google API, yaitu: Maps SDK for Android, Directions API, Distance Matrix API, Geocoding API, Geolocation API, Maps Javascript API, Places API, dan Maps Static API. Semua API ini dibutuhkan untuk menampilkan informasi data spasial dan non spasial di map ketiga sistem diatas.

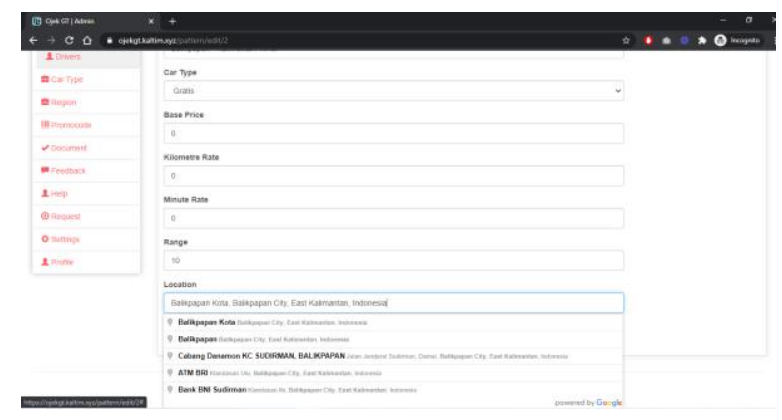

Gambar 7. Pengelolaan Wilayah Driver

\section{Dengan Google API}


Selain pengelolaan wilayah, dalam sistem ini juga ditambahkan pengaturan harga dasar, harga tambahan per kilometer, harga per menit, dan jarak maksimal. Pengaturan ini untuk mengakomodir paket atau promosi lain yang membutuhkan perhitungan tersebut.

Sistem admin berbasis framework Codeigniter ini nantinya akan dikembangkan lebih lanjut sesuai dengan kebutuhan user. Salah satu target kedepannya adalah penambahan layanan antar makanan, barang, dan monitoring lokasi driver.

Dalam sistem untuk pelanggan yang berbasis Android, pengguna dapat melakukan pemesanan transportasi, melihat pesanan yang telah dilakukan, menambahkan kode promosi, dan melakukan perubahan pengaturan nama, email, dan nomor telepon.

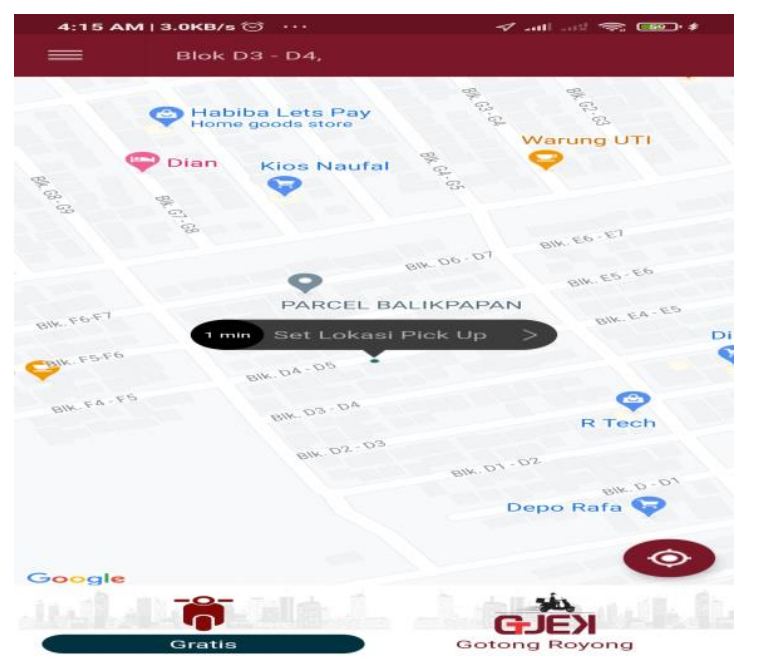

Gambar 8. Halaman Utama Ojek GT

\section{Pelanggan}

Tampilan map dirancang untuk menampilkan arah jalan, nama jalan, nama tempat, dan marker-marker jalan lainnya. Selain itu, pengguna dapat menambahkan informasi lokasi rumah dan kantornya untuk mengakses pesanan lebih cepat.

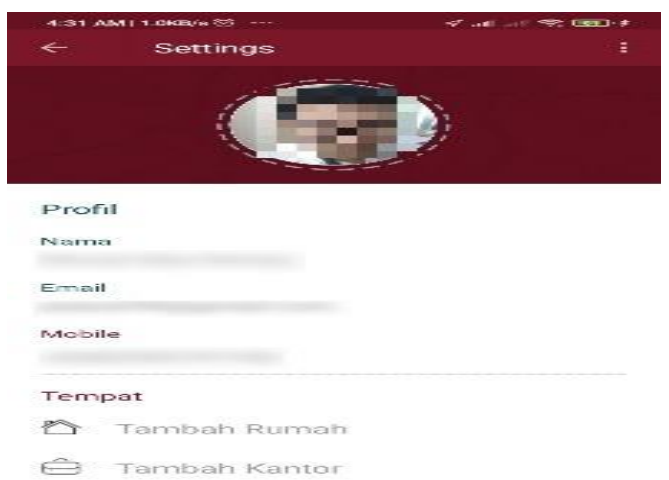

\section{Gambar 9. Halaman Profil Pengguna}

Aplikasi ini juga telah dipublikasikan ke Google Play agar dapat diakses dan diunduh langsung oleh masyarakat. Kedepannya, aplikasi ini akan dikembangkan lagi dengan fitur-fitur lainnya seperti: pemesanan makanan, pengiriman barang, dan layanan-layanan lainnya.

Sedangkan untuk Aplikasi driver, pengguna dapat melakukan perubahan status dari online untuk menerima order atau offline untuk berhenti menerima order. Pengguna juga dapat mengakses ringkasan order yang telah dia lakukan hari ini di halaman utama, serta mengakses fitur lainnya melalui halaman utama.

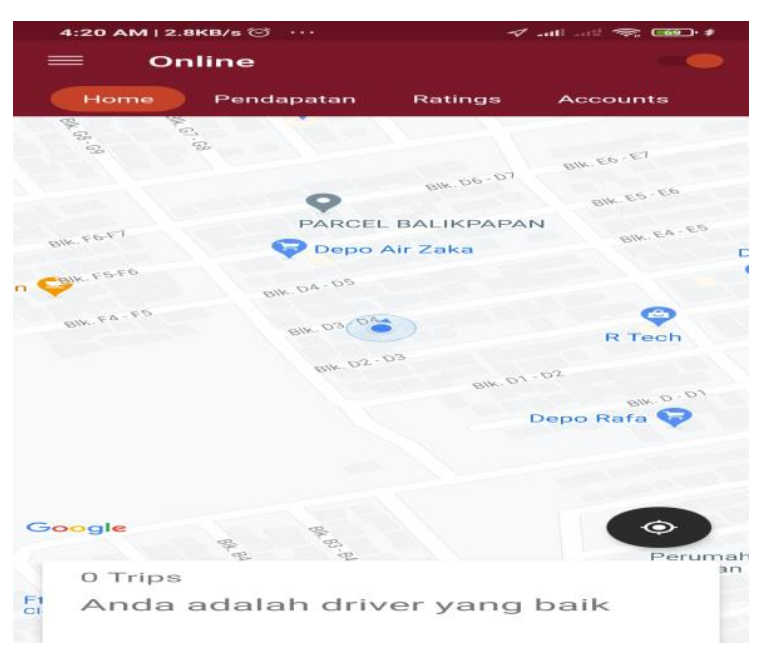

\section{Gambar 10. Halaman Utama Driver}

Selain itu, pengguna dapat melihat informasi lengkap setiap order, rating, dan kelengkapan dokumen-dokumennya beserta 
status approvalnya melalui aplikasi ini. Sedangkan informasi dalam map disajikan sama seperti informasi di aplikasi pelanggan.

Kedua sistem ini juga dilengkapi dengan API Firebase yang menyimpan data dalam format Javascript Object Notation (JSON) tanpa penggunaan query untuk Create, Read, Update, and Delete (CRUD) [8] dan sesuai dengan kebutuhan ketiga sistem yang dirancang. API ini juga digunakan dalam verifikasi nomor handphone user menggunakan Short Message Service (SMS).

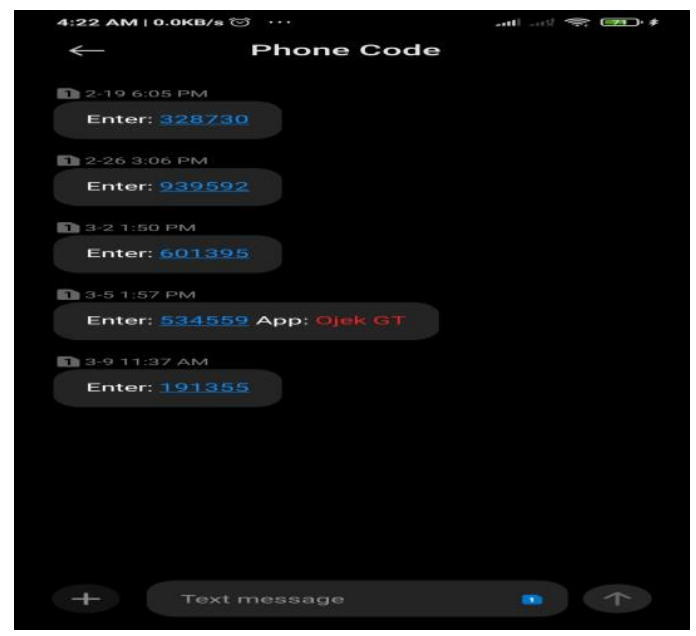

Gambar 11. SMS Verifikasi Menggunakan Google Firebase

Berdasarkan rancangan diatas, dapat disimpulkan bahwa integrasi sistem ini telah sesuai dengan target awal perancangan dan penerapan sistem. Keamanan data dalam aplikasi merupakan salah satu permasalahan yang kerap terjadi dalam proses integrasi[9], sehingga harus dilakukan mitigasi. Sistem pengguna, driver, dan admin telah terintegrasi dengan sempurna ke dalam basis data melalui pemanfaatan API sehingga sistem dapat berjalan dengan baik.

\section{KESIMPULAN}

Berdasarkan pembahasan diatas, dapat disimpulkan bahwa:

1. Penerapan aplikasi ini telah sesuai dengan prinsip Society 5.0 dimana semua lapisan masyarakat dapat mengakses dan menggunakannya.

2. Alur CSFT dapat diterapkan dengan baik dalam aplikasi ini sehingga sesuai dengan target rancang bangun yang telah ditetapkan.

3. Integrasi dan pemanfaatan API dalam sistem ini sangat membantu dalam proses pengembangan aplikasi dan keamanan aplikasi ini.

4. Kedepannya aplikasi ini akan dirancang untuk memenuhi fungsi-fungsi lainnya seperti: pemesanan makanan, antar barang, dan layanan-layanan lainnya.

\section{UCAPAN TERIMA KASIH}

Direktorat Riset dan Pengabdian Masyarakat Direktorat Jenderal Penguatan Riset dan Pengembangan Kementerian Riset dan Teknologi/ Badan Riset dan Inovasi Nasional sesuai dengan Kontrak Pengabdian Kepada Masyarakat Tahun 2020.

\section{DAFTAR PUSTAKA}

[1] Skobelev, P. O., \& Borovik, S. Y. (2017). On the way from Industry 4.0 to Industry 5.0: from digital manufacturing to digital society. Industry 4.0, 2(6), 307-311

[2] Roring, Riovan Styx, and Kusrini Kusrini. "Integrasi Sistem berbasis Predictive Analytics untuk Pasar Tradisional Indonesia." CSRID (Computer Science 
Research and Its Development Journal) 9.1 (2017): 21-30.

[3] Jacob, Pramod Mathew, and M. Prasanna. "A Comparative analysis on Black box testing strategies." 2016 International Conference on Information Science (ICIS). IEEE, 2016.

[4] Das, Ripunjit, and Lakshmi Prasad Saikia. "Comparison of Procedural PHP with Codeigniter and Laravel Framework." International Journal of Current Trends in Engineering \& Research 2.6 (2016): 42-8.

[5] Fraczek, Konrad, and Malgorzata Plechawska-Wojcik. "Comparative analysis of relational and non-relational databases in the context of performance in web applications." International Conference: Beyond Databases, Architectures and Structures. Springer, Cham, 2017.

[6] Sohan, S. M., et al. "A study of the effectiveness of usage examples in REST API documentation." 2017 IEEE Symposium on Visual Languages and Human-Centric Computing (VL/HCC). IEEE, 2017.

[7] Wu, Hao. "Comparing Google Maps and Uber Movement travel time data." Transp. Find (2019).

[8] Khawas, Chunnu, and Pritam Shah. "Application of firebase in android app development-a study." International Journal of Computer Applications 179.46 (2018): 49-53.

[9] Anugrah, Indra Gita, and Muhamad Aldi Rifai Imam Fakhruddin. "Development Authentication and Authorization Systems of Multi Information Systems Based REst API and Auth Token." INNOVATION RESEARCH JOURNAL 1.2 (2020): 127132. 